Revista Grifos - Unochapecó

\title{
SUICÍDIOS DE FUMICULTORES E ATUAÇÃO DOS AGENTES DE EXTENSÃO RURAL PÚBLICA NO VALE DO RIO PARDO/RS ${ }^{1}$
}

\author{
SUICIDES OF TOBACCO FARMERS AND WORK OF PUBLIC RURAL EXTENSION AGENTS IN \\ VALE DO RIO PARDO/RS
}

\section{SUICIDIOS DE PRODUCTORES DE TABACO Y ACTUACIÓN DE AGENTES PÚBLICOS DE EXTENSIÓN RURAL EN EL VALE DO RIO PARDO/RS}

\author{
Laila Mayara Drebes ${ }^{2}$ \\ https://orcid.org/0000-0002-0681-238X \\ Joel Orlando Bevilaqua Marin ${ }^{3}$ \\ https://orcid.org/0000-0001-7438-7939
}

Submissão: 30/01/2020 / Aceito: 01/03/2021 / Publicado: 31/03/2021.

\begin{abstract}
Resumo
$\mathrm{O}$ artigo analisa o quadro institucional de ações e representações sociais construído pelo serviço público de extensão rural para o posicionamento de seus agentes frente aos suicídios de fumicultores no Vale do Rio Pardo/RS. Consiste em um estudo de caso cujos dados foram coletados por meio de entrevistas semiestruturadas com agentes de extensão rural e, complementarmente, pesquisa bibliográfica e documental. Os resultados evidenciam que os fumicultores não são inteiramente reconhecidos como integrantes da categoria socioprofissional agricultura familiar, não sendo facultado aos mesmos o usufruto de benefícios ofertados a outros agricultores familiares. Quando recebem atenção dos agentes do serviço público de extensão rural, os fumicultores são alvos de tentativas de implementação de ações de diversificação produtiva para redução das áreas de fumicultura. Ações como essas são compreendidas pelos fumicultores como desvalorização de seu trabalho, o que pode contribuir para crises identitárias e, consequentemente, suicídios. Portanto, apesar de visualizado como instrumento de resolução de problemas nas áreas rurais, o serviço público de extensão rural não pode ser assim compreendido no âmbito de prevenção dos suicídios de fumicultores: na visão de seus agentes, os suicídios são casos de saúde pública.
\end{abstract}

Palavras-chave: Agricultura familiar. Convenção Quadro para Controle do Tabaco. Diversificação produtiva. Políticas públicas. Sistema integrado de produção.

\footnotetext{
Abstract

The article analyzes the institutional framework of social actions and representations built by the public service of rural extension for the positioning your agents in the face of the suicides

${ }^{1} \mathrm{O}$ presente trabalho foi realizado com apoio da Coordenação de Aperfeiçoamento de Pessoal de Nível Superior - Brasil (CAPES) - Código de Financiamento 001.

${ }^{2}$ Doutora em Extensão Rural, Professora do Instituto de Estudos do Trópico Úmido (IETU) e do Programa de Pós-Graduação em Dinâmicas Territoriais e Sociedade na Amazônia (PDTSA) da Universidade Federal do Sul e Sudeste do Pará (UNIFESSPA). Xinguara/PA, Brasil. E-mail: drebeslm@ gmail.com.

${ }^{3}$ Doutor em Sociologia, Professor do Programa de Pós-Graduação em Extensão Rural (PPGEXR) da Universidade Federal de Santa Maria (UFSM). Santa Maria/RS, Brasil. E-mail: bevilaquamarin@gmail.com.
} 
of tobacco farmers in the Vale do Rio Pardo/RS. It consists of a case study whose data were collected through semi-structured interviews with rural extension agents and, in addition, bibliographic and documentary research. The results show that tobacco farmers are not fully recognized as members of the family farm socio-professional category, and they are not allowed to enjoy the benefits offered to other family farmers. When they receive attention from the public service of rural extension agents', tobacco farmers are targets of attempts to implement productive diversification actions to reduce tobacco growing areas. Actions like these are understood by tobacco farmers as devaluing their work, which can contribute to identity crises and, consequently, suicides. Therefore, despite being viewed as a problemsolving tool in rural areas, the public service of rural extension cannot be understood as such in the context of the prevention of suicide of tobacco farmers: in the view of their agents, the suicides are public health cases.

Keywords: Family farming. Framework Convention on Tobacco Control. Productive diversification. Public policy. Integrated production system.

\section{Resumen}

El artículo analiza el marco institucional de acciones y representaciones sociales construido por el servicio público de extensión rural para el posicionamiento de sus agentes frente a los suicidios de los productores de tabaco en el Vale do Rio Pardo/RS. Consiste en un estudio de caso cuyos datos fueron recolectados a través de entrevistas semiestructuradas con extensionistas rurales y, además, investigación bibliográfica y documental. Los resultados muestran que los productores de tabaco no están plenamente reconocidos como miembros de la categoría socioprofesional de agricultura familiar, y no se les permite disfrutar de los beneficios ofrecidos a otros agricultores familiares. Cuando reciben atención de los agentes del servicio público de extensión rural, los productores de tabaco son blanco de intentos de implementar acciones de diversificación productiva para reducir las áreas de cultivo de tabaco. Acciones como estas son entendidas por los cultivadores de tabaco como una devaluación de su trabajo, lo que puede contribuir a crisis de identidad y, en consecuencia, suicidios. Por tanto, a pesar de ser visto como una herramienta de resolución de problemas en las zonas rurales, el servicio público de extensión rural no puede entenderse en el contexto de la prevención del suicidio entre los productores de tabaco: a juicio de sus agentes, los suicidios son casos de salud pública.

Palabras chave: Agricultura familiar. Convenio Marco para el Control del Tabaco. Diversificación productiva. Políticas públicas. Sistema de producción integrado.

\section{INTRODUÇão}

O Brasil ocupa a segunda posição no ranking mundial de produção de tabaco, ficando atrás apenas da China. Entre os estados brasileiros, o Rio Grande do Sul se destaca como o principal produtor do chamado fumo em folha, visto que apresenta várias regiões especializadas na fumicultura, com destaque para o Vale do Rio Pardo. Caracterizada por processo de colonização germânica, a história da fumicultura na região do Vale do Rio Pardo se confunde com esse povoamento, pois desde a instauração das primeiras colônias alemãs, 
ainda no século XIX, o tabaco foi cultivado nesse território, sendo a atividade gradativamente transformada de uma economia de escopo para uma economia de escala, atualmente organizada por meio de um complexo agroindustrial cada vez mais globalizado.

Dessa maneira, o Vale do Rio Pardo é contemporaneamente reconhecido como o principal polo nacional de produção e processamento de tabaco, pois além de nove de seus municípios estarem entre os maiores produtores do país, o território também é sede de grande parte das principais agroindústrias responsáveis pela transformação do produto em cigarros e congêneres, sendo elas vinculadas a corporações internacionais como British American Tobacco, China Tobacco, Imperial Brands, Japan Tobacco International, Philip Morris International, entre outras.

Mas além do título de sede do complexo agroindustrial fumageiro, o Vale do Rio Pardo também se tornou famoso devido às elevadas taxas de suicídio. Em comparação ao Brasil e ao Rio Grande do Sul, a região apresenta taxa de suicídios praticamente 2,0 (duas) e 3,0 (três) vezes maior, respectivamente. Segundo dados da Secretaria Estadual da Saúde do Rio Grande do Sul (RIO GRANDE DO SUL, 2018), no Vale do Rio Pardo ocorrem cerca de 17,2 suicídios a cada 100.000 habitantes.

Mesmo diante da subnotificação dos casos de suicídios e da inexistência de um registro sistematizado dessas mortes de acordo com a profissão das vítimas, condições que não permitem identificar com precisão a quantidade de fumicultores que cometem suicídio, os dados anteriormente apresentados sugerem nexos causais entre os suicídios e as particularidades das condições e relações sociais do trabalho no âmbito do complexo agroindustrial fumageiro, como elucidado nos estudos de Falk et al. (1996), Almeida (2005), Meneghel et al. (2012), Faria et al. (2014) e Peres e Neto (2018). Embora os estudos atestem a ocorrência de suicídios de fumicultores no Vale do Rio Pardo, principalmente entre adultos, do sexo masculino e de descendência germânica, utilizando o método do enforcamento, as causas desses suicídios ainda não são claras (DREBES, 2019).

Determinar com precisão os motivos dos suicídios de fumicultores não é um empreendimento simples, pois no Vale do Rio Pardo estruturou-se um campo de poder, no sentido bourdieusiano, no entorno desta cadeia produtiva. Conforme os escritos de Bourdieu (2003; 2011), o campo é um espaço social determinado por normas sociais particulares, no qual os agentes sociais que possuem certas condições materiais e simbólicas relacionam-se de maneira concorrencial entre si, estruturando o campo a partir das posições que nele 
ocupam. Em síntese, essas relações sociais são conflituosas, pois os agentes lutam para obter mais capitais no interior do campo de poder, visando ou mantê-lo ou subvertê-lo.

Assim, no campo de poder percebido no Vale do Rio Pardo, os agentes das instituições sociais envolvidas na fumicultura disputam entre si para tentar perpetuar suas próprias verdades sobre a atividade, priorizando os seus próprios interesses institucionais. Por exemplo, enquanto os representantes das agroindústrias fumageiras são favoráveis à atividade, pois necessitam dela para sua manutenção socioeconômica, os agentes do serviço de saúde pública são desfavoráveis, pois ela não contribui para a vitalidade da população ao dar origem aos cigarros e, consequentemente, ao tabagismo. Assim, agentes de diversas outras instituições sociais também permeiam este campo de poder, construindo suas próprias ações e representações orientadas no sentido de conter ou de incrementar a fumicultura.

Vale destacar que a ocorrência de suicídios de fumicultores aguça ainda mais as divergências institucionais no cerne desse campo de poder, gerando a coexistência de narrativas causais distintas, muitas vezes conflitantes entre si. Tais narrativas causais são derivadas de quadros institucionais socialmente construídos em conformidade com a posição que cada instituição inserida no campo de poder da fumicultura ocupa no mesmo com vistas a preservar suas preferências. Dessa maneira, os agentes de cada instituição acionam suas ações e representações sociais não só na tentativa de identificar as causas dos suicídios de fumicultores, mas, sobretudo, de eximir-se de uma possível culpa e/ou responsabilidade por estas mortes.

No Vale do Rio Pardo, percebe-se que este campo de poder é permeado por agentes das seguintes instituições sociais: famílias e comunidades de fumicultores; agroindústrias fumageiras; serviço de saúde pública; serviço público de extensão rural; igreja; imprensa; e organizações não-governamentais de prevenção de suicídio. Nesse estudo, o foco recai sobre os agentes do serviço público de extensão rural, que, no estado do Rio Grande do Sul, é implementado pela Emater/ASCAR.

Diante disso, o presente artigo tem por intuito analisar o quadro institucional de ações e de representações sociais construído pelo serviço público de extensão rural para o posicionamento de seus agentes frente ao fenômeno de suicídios de fumicultores no Vale do Rio Pardo/RS. O estudo é derivado da tese de doutorado intitulada "Suicídios de fumicultores familiares: construções de um problema social”, defendida no ano de 2019, no Programa de Pós-Graduação em Extensão Rural (PPGExR) da Universidade Federal de Santa Maria 
(UFSM), de autoria de Laila Mayara Drebes e orientação de Joel Orlando Bevilaqua Marin. Especificamente, o artigo é fruto do quarto capítulo da tese, que versou sobre o Estado, analisando o serviço de saúde pública e o serviço público de extensão rural. Vale destacar, ainda, que uma versão preliminar do estudo foi anteriormente publicada nos anais do $58^{\circ}$ Congresso da Sociedade Brasileira de Economia, Administração e Sociologia Rural (SOBER).

Em termos metodológicos, foi conduzido um estudo de caso de natureza qualitativa em município não identificado do Vale do Rio Pardo (para preservar a identidade dos agentes sociais englobados pela pesquisa). Para a referida tese de doutorado foram realizadas 24 (vinte e quatro) entrevistas, sendo 5 (cinco) delas com agentes do serviço público de extensão rural, as quais serviram como fundamento para a redação do artigo aqui apresentado. Adicionalmente, também foi consultada literatura científica relacionada ao tema de estudo e documentos, tais como textos de políticas públicas.

Em virtude da delicadeza do tema, é relevante ressaltar a conformidade da coleta de dados com as considerações éticas referentes ao estudo com seres humanos, encontradas na Resolução 466 de 2012 do Conselho Nacional de Saúde (BRASIL, 2012), sendo a pesquisa autorizada pelo Comitê de Ética em Pesquisa com Seres Humanos (CEP) da Universidade Federal de Santa Maria (UFSM) e inscrita na Plataforma Brasil sob número CAAE 66561617.1 .0000 .5346$.

A partir desta introdução, o estudo foi dividido em três seções. Na primeira delas, é apresentada uma retomada da construção social da categoria socioprofissional agricultura familiar no Brasil, público prioritário do serviço público de extensão rural, ponderando sobre sua capacidade de incorporação dos fumicultores. Na segunda seção, são analisadas as políticas públicas implementadas pela extensão rural e suas consequências sobre a fumicultura. Por fim, nas considerações finais são sintetizadas as principais descobertas do estudo, com vistas à conclusão.

\section{A fumicultura no ÂMbito da Agricultura Familiar: CONSTRUÇão social de UM ESTIGMA}

De acordo com Neves (2007), nos Estados Unidos, na década de 1980, já eram encontrados estudos utilizando o conceito family farm (agricultura familiar) ou ainda family 
farmer (agricultor familiar). Este conceito servia à caracterização da industrialização das atividades agropecuárias, designando os agricultores adeptos à modernização da agricultura, isto é, vinculados à indústria fornecedora de insumos agropecuários, situada "antes da porteira". Como elucidado por Mazoyer e Roudart (2010), tais insumos industriais eram derivados de processos de motomecanização (desenvolvimento de tratores, máquinas, implementos, conjuntos de ordenha, resfriadores, etc.), quimificação (desenvolvimento de agrotóxicos, antibióticos, fertilizantes, vacinas, etc.) e seleção (melhoramento genético animal e vegetal) aplicados às atividades agropecuárias.

Contudo, aquilo que os norte-americanos denominavam de family farm era intitulado pelos brasileiros de agricultura integrada ou, ainda, agricultura tecnificada: ambas expressões utilizadas para se referir aos agricultores com condições socioeconômicas de adesão a esses pacotes tecnológicos industriais, os quais foram incentivados tanto pela pesquisa agropecuária, quanto pela extensão rural pública brasileira. Termos como grandes agricultores e agricultores capitalizados também cabiam nessa designação. Diante disso, é relevante adiantar que aqui no Brasil o conceito de agricultura familiar acabou sendo empregado com um significado distinto do original norte-americano.

Até o final do século XX, não era comum encontrar a expressão agricultura familiar aplicada ao contex to brasileiro. Esse cenário começou a ser transformado na década de 1990, em virtude da combinação de uma série de eventos transcorridos nos campos da pesquisa e da política do país, os quais permitiram a construção do conceito de agricultura familiar em consonância com as características espaço-temporais do rural nacional.

De acordo com Schneider (2006), o primeiro evento a ser considerado aconteceu na esfera dos movimentos sociais e sindicais. Em meados da década de 1990, desencadeou-se uma efervescência desses movimentos, que reivindicavam o reconhecimento das necessidades dos agricultores excluídos do processo de modernização da agricultura. Esta atuação dos movimentos sociais e sindicais consolidou-se com a realização de eventos reivindicatórios anuais chamados Gritos da Terra, existentes até os dias atuais.

O segundo evento salientado, intimamente relacionado com o primeiro, foi a criação de uma política pública como resposta às pressões dos movimentos acima descritos. Destarte, em 1996, foi instituído o Programa Nacional de Fortalecimento da Agricultura Familiar (PRONAF), com a finalidade de conceder crédito ao desenvolvimento das atividades agropecuárias daqueles que não podiam ser enquadrados como agricultores capitalizados, 
integrados, tecnificados ou, ainda, grandes agricultores, os quais encontravam-se em sérias dificuldades de manutenção de suas atividades produtivas. Com o PRONAF, os movimentos sociais e sindicais rurais reforçaram ainda mais as reivindicações de comprometimento do Estado com esse público, o qual necessitava de políticas públicas diferenciadas (SCHNEIDER, 2006).

O terceiro evento foi a reorientação das discussões acadêmicas sobre as áreas rurais. Na segunda metade da década de 1990, assistiu-se a uma relativa retomada dos estudos rurais no Brasil, até então reduzidamente visados entre os cientistas. Diante dos dois eventos anteriores, os pesquisadores ampliaram as problemáticas de interesse, indo para além das consequências da modernização da agricultura, já ostensivamente analisadas (SCHNEIDER, 2006). Como ressaltado no estudo de Picolotto (2011), oportunamente intitulado "as mãos que alimentam a nação", entre estas temáticas estava a relevância socioeconômica dos até então designados pequenos agricultores para a produção de alimentos, o que possibilitou o reconhecimento da agricultura familiar como uma categoria dinâmica e produtiva.

Conjuntamente, estes eventos legitimaram a criação, a consolidação e a disseminação do conceito de agricultura familiar no Brasil, com o intuito de reunir, reconhecer e valorizar os mais variados estratos de agricultores excluídos da modernização da agricultura, até então considerados como atrasados e dispersos sob distintas expressões, como pequenos produtores, pequenos proprietários, camponeses, agricultores de subsistência, agricultores de baixa renda, colonos, meeiros, parceiros, arrendatários, posseiros, entre outros. Nesse sentido, no Brasil, a agricultura familiar foi socialmente construída como uma categoria socioprofissional cujo objetivo consistia em alavancar um processo de positivação ideológica destes agricultores até então relegados, ofertando políticas públicas especiais de assistência técnica e de crédito (NEVES, 2007).

Os estudiosos do assunto concordam com algumas características úteis à elaboração do conceito de agricultura familiar. Estas características confluem sobre a interdependência existente entre terra, trabalho e família, recobrindo situações extremamente variáveis. $\mathrm{Na}$ visão de Schneider (2006), são os vínculos familiares estabelecidos entre os membros, assim como as suas normas de transmissão do patrimônio - envolvendo acervos materiais e simbólicos -, os elementos mais relevantes na conceituação de agricultura familiar. Mas dada a infinidade de situações passíveis de serem compreendidas como agricultura familiar, Neves 
(2007) assinala a necessidade de normativas jurídicas para uma delimitação precisa desse público.

Logo, desde o início do reconhecimento da referida categoria socioprofissional, o Estado vem elaborando regras que enquadram, ou não, os agricultores nesses termos. De início, o enquadramento foi promovido por meio do estatuto de acesso ao PRONAF. Depois, pela Lei 11.326, de 24 de julho de 2006, que estabeleceu as diretrizes para a formulação da Política Nacional da Agricultura Familiar e Empreendimentos Familiares Rurais (BRASIL, 2006). Atualmente, ocorre por meio do Decreto 9.064, de 31 de maio de 2017, que dispõe sobre a Unidade Familiar de Produção Agrária, institui o Cadastro Nacional da Agricultura Familiar e regulamenta a Lei 11.326 anteriormente mencionada (BRASIL, 2017).

Assim, de acordo com o Decreto 9.064/2017, entende-se como agricultura familiar aquela que: 1) possui, a qualquer título, área de até quatro módulos fiscais; 2) utiliza, no mínimo, metade da força de trabalho familiar no processo produtivo e de geração de renda; 3) aufere, no mínimo, metade da renda familiar de atividades econômicas do seu estabelecimento ou empreendimento; 4) possui a gestão do estabelecimento ou do empreendimento estritamente familiar (BRASIL, 2017).

Em somatório ao enquadramento jurídico, embora não decretado, desde o início desse processo de construção social existiu um enquadramento simbólico que responsabilizou a agricultura familiar pela produção de alimentos, como anteriormente mencionado. Esta premissa se relaciona com o fato de parte desses agricultores estarem supostamente desarticulados do chamado agronegócio, cujos principais produtos consistem em commodities agrícolas, isto é, produtos agropecuários uniformes, possíveis de serem estocados e cujos preços são formados no mercado externo, conforme oferta e demanda internacionais. Muitas commodities agrícolas não são destinadas à alimentação humana ou representam parcela pouco significativa na mesma.

Conforme o estudo de Anjos et al. (2008), sobre o Rio Grande do Sul, a incorporação do pacote tecnológico promovido pelo processo de modernização da agricultura conduziu muitas propriedades rurais à especialização na produção de commodities agrícolas, tais como a soja e, também, outros produtos agropecuários gerados em regime de integração vertical, como o próprio tabaco. Essa especialização na produção de commodities agrícolas reduziu drasticamente a produção daqueles alimentos frequentemente encontrados na mesa dos brasileiros. 
Vale destacar que este enquadramento simbólico se tornou mais contundente no decorrer dos anos 2000, sendo reforçado por meio da elaboração de uma série de políticas públicas em favor da produção de gêneros alimentícios no âmbito da agricultura familiar, como a versão Mais Alimentos do PRONAF, o Programa de Aquisição de Alimentos (PAA), o Programa Nacional de Alimentação Escolar (PNAE) e a própria Política Nacional de Assistência Técnica e Extensão Rural (PNATER). Essa última, não só instituiu os agricultores familiares como público prioritário do serviço de extensão rural, como apresentou, entre os seus princípios, a proposta de contribuir para a segurança e soberania alimentar e nutricional (BRASIL, 2010a), reforçando o vínculo entre agricultores familiares e gêneros alimentícios.

Estas políticas públicas encontraram sustentação nos dados dos últimos Censos Agropecuários, que vem evidenciando a importância socioeconômica dos agricultores familiares para a produção dos principais alimentos presentes na dieta dos brasileiros. Conforme o Censo Agropecuário de 2017, a agricultura familiar envolve $77 \%$ dos estabelecimentos, ocupando somente $23 \%$ das áreas, mas ainda assim produz uma série de produtos alimentícios de origem vegetal e animal, como é o caso do aipim e do feijão, por exemplo (IBGE, 2017).

Mas, e como fica a fumicultura diante de tudo isso? Pois bem, a observação da realidade empírica do Vale do Rio Pardo, famosa região produtora de tabaco situada no Rio Grande do Sul, permite perceber a adequação da fumicultura à inter-relação existente entre os fatores de produção terra, trabalho e família. Os estabelecimentos dedicados à fumicultura são caracterizados por pequenas propriedades rurais, situadas em áreas de terra pouco favoráveis ao processo de mecanização, resultando em elevada demanda de mão-de-obra familiar no trabalho produtivo. Além disso, essas características provocam uma tendência de especialização na fumicultura, que acaba se configurando como a principal fonte de renda para esses agricultores e suas famílias. Esse conjunto de atributos demonstra a conformidade da realidade dos fumicultores do Vale do Rio Pardo com o enquadramento jurídico de agricultura familiar vigente no país contemporaneamente.

Contudo, a fumicultura contradiz o requisito de produção de gêneros alimentícios, que com as políticas públicas anteriormente citadas, saiu do âmbito simbólico e ganhou materialidade. O produto agropecuário gerado pela fumicultura não é alimento, nem mesmo é saudável. A fumicultura é a atividade agropecuária responsável pela produção de cigarros 
e congêneres, considerados drogas lícitas no Brasil. Essas drogas são responsáveis pelo tabagismo, que consiste na dependência de nicotina e que tem vinculação com mais de cinquenta enfermidades conhecidas, perpassando por câncer, doenças cardiovasculares e doenças respiratórias, entre outras. De acordo com estimativas do Instituto Nacional do Câncer (INCA), diariamente, cerca de 428 brasileiros morrem em decorrência do tabagismo (INCA, 2020). Como bem sintetizou um agente da extensão rural pública entrevistado: “ $o$ tabaco não é alimento, é um vício, uma droga legalizada" (Valdir, 55 anos, extensionista rural e ex-instrutor de tabaco).

Em virtude disso, mesmo podendo ser enquadrados como agricultores familiares conforme a legislação vigente, os fumicultores não desfrutam das conveniências consagradas a outras atividades produtivas entendidas como próprias da agricultura familiar. $\mathrm{O}$ fato de não produzir gêneros alimentícios coloca a fumicultura em posição de afronta ao processo de positivação ideológica que deu origem à categoria socioprofissional agricultor familiar no país, fazendo com que os fumicultores sofram restrições no acesso a políticas públicas destinadas à agricultura familiar. Como destacado no estudo de Gazolla e Schneider (2013), desde o ano de 2003, existe interdição do acesso dos fumicultores ao PRONAF. Atualmente, o acesso à essa política pública submete-se à comprovação de $30 \%$ da renda vinda de outras atividades agropecuárias.

Outra situação contraditória é verificada no acesso dos fumicultores ao serviço de extensão rural enquanto política pública, o qual desde o início dos anos 2000 possui os agricultores familiares como público prioritário (BRASIL, 2010a), como anteriormente mencionado. Além de por si só constituir uma política pública, o serviço de extensão rural é responsável por implementar as políticas públicas para os agricultores familiares. As contradições que permeiam a relação entre agricultura familiar e fumicultura emergiram nos relatos dos próprios extensionistas rurais entrevistados, como evidenciado abaixo.

[...] Não quer dizer que o fumicultor não vai ser assistido. Porque ele trabalha com solo, trabalha com ambiente, então sempre vai ter uma inserção dentro daquela propriedade. Embora a gente não dê assistência para a fumicultura, damos assistência para o fumicultor, porque ele trabalha com solo, com milho, com alimento, muitos que são fumicultores também produzem hortaliças para venda em feiras, então a gente tem também uma inserção dentro dessas propriedades (Antônio, 37 anos, extensionista rural). 
O relato evidencia que os extensionistas rurais não fornecem assistência técnica para a fumicultura, mas ainda assim prestam serviços de extensão rural aos fumicultores se esses praticam outra atividade, para além da fumicultura. Somente se isolados da fumicultura em si - em virtude da existência de outras atividades de cultivos e/ou criações alimentares -, os fumicultores são visualizados como integrantes da categoria socioprofissional de agricultura familiar, considerados aptos a acessar o serviço de extensão rural. De acordo com Deponti e Schneider (2013), em estudo sobre a ação extensionista na fumicultura em Dom Feliciano, no Rio Grande do Sul, os extensionistas rurais realizam intervenções somente nos estabelecimentos rurais de fumicultores com interesse na diversificação das atividades agropecuárias, deixando os demais vulneráveis e à mercê de uma assistência meramente técnica, proporcionada pelos instrutores contratados pelas agroindústrias fumageiras.

Outrossim, também é necessário destacar a influência do especializado sistema integrado de produção encontrado na fumicultura como outra característica que destoa das premissas que levaram à construção social da categoria socioprofissional da agricultura familiar no Brasil. Conforme Paulilo (1990, p. 19), em estudo desenvolvido em Santa Catarina, o sistema integrado de produção é definido como "uma forma de articulação vertical entre empresas agroindustriais e pequenos produtores agrícolas, em que o processo de produção é organizado industrialmente, ou o mais próximo possível deste modelo, com aplicação maciça de tecnologia e capital”. Para Melz (2017), com base na experiência do Vale do Rio Pardo, o sistema integrado consiste em um intrincado sistema de compromissos estipulados contratualmente entre os responsáveis pela produção (parte dos agricultores) e os responsáveis pelo processamento (parte das agroindústrias), visando - supostamente proventos para ambas as partes.

\footnotetext{
O sistema integrado de produção de tabaco consiste em contratos entre indústria e fumicultores: as empresas fornecem um pacote tecnológico composto de insumos agrícolas (sementes, fertilizantes, agrotóxicos, entre outros) e prestação de assistência técnica aos agricultores. O fumicultor, por sua vez, produz o fumo de acordo com as instruções técnicas e entrega o tabaco produzido à empresa contratante, que adquire a produção contratada naquela safra. A empresa desconta o valor dos materiais fornecidos e repassa o saldo correspondente aos produtores (MELZ, 2017, p. 21).
}

Dessa forma, a adesão da fumicultura do Vale do Rio Pardo ao sistema integrado não se mostra condizente com o cenário de carência de assistência técnica e de tecnologia que alavancou a geração da categoria agricultura familiar no país, já que as agroindústrias 
fumageiras garantem ambos os benefícios aos agricultores integrados. Assim, não apenas o simbolismo de produção alimentícia fomentado pelas políticas públicas, mas a própria lógica do sistema integrado de produção de tabaco contribuiu para agravar as contradições que atravessam a relação entre agricultura familiar e fumicultura, como evidenciado nos relatos dos extensionistas rurais entrevistados:

\begin{abstract}
O foco é o agricultor, no caso, o meio rural. É um atendimento bastante grande destinado ao agricultor familiar. [...] Nossas funções principais são na produção de grãos, milho, soja, arroz, que são os principais; as frutas, hortaliças, a parte ambiental também [...]. Aqui também trabalhamos a parte de agroindústrias, desde o início até a regularização da parte fiscal. E depois tem uma gama de outras atividades, a piscicultura também... [...]. A fumicultura diretamente não, não na cultura em si. Fica mais com as empresas fumageiras mesmo. Na fumicultura, a gente trabalha mais com a conservação de solo, com a parte ambiental, não com a condução da cultura em si, porque daí, como é uma atividade integrada, com contrato, no caso a responsável é a empresa (Valdir, 55 anos, extensionista rural e ex-instrutor de tabaco).
\end{abstract}

Nesse sentido, o afastamento dos extensionistas rurais dos fumicultores não se deve exclusivamente ao fato de as políticas públicas priorizarem o atendimento de agricultores familiares que produzem gêneros alimentícios, mas também ao fato de que os fumicultores já recebem assistência técnica por parte dos instrutores de tabaco das integradoras.

Devido a esse intrincado panorama, o reconhecimento dos fumicultores no âmbito da agricultura familiar é atravessado por constrangimentos. Percebe-se que o processo de construção social da categoria socioprofissional da agricultura familiar, que perpassa por atributos materiais e simbólicos, também foi o processo de construção social de um estigma acerca da fumicultura, agravado por certas características do sistema integrado de produção de tabaco.

Desse modo, mesmo se enquadrando nas premissas jurídicas da agricultura familiar, a fumicultura apresenta alguns atributos que se desencontram das motivações desencadeadoras da elaboração dessa categoria socioprofissional e do próprio imaginário social materializado por meio de políticas públicas que vinculam a agricultura familiar à produção de alimentos. Devido a essas contradições, aos fumicultores não é facultado o usufruto de benefícios assegurados a outros agricultores familiares, afetando, até mesmo, o atendimento realizado pelos agentes do serviço público de extensão rural. 


\section{OS AGENTES DE EXTENSÃO RURAL DIANTE DOS SUICÍDIOS DE FUMICULTORES}

$\mathrm{Na}$ seção anterior, foi possível perceber que a forma como a categoria socioprofissional da agricultura familiar foi socialmente construída no Brasil engendrou algumas contradições entre agricultura familiar e fumicultura, dificultando o acesso dos fumicultores a certas políticas públicas elaboradas para agricultores familiares e colocadas em prática pelo serviço público de extensão rural, o que, por sua vez, contribuiu com a promoção de uma estigmatização da atividade em si.

No Brasil, para além do mencionado, a estigmatização da fumicultura foi acentuada a partir do ano de 2005, com a adesão do país à Convenção Quadro para o Controle do Tabaco (CQCT), elaborada no âmbito da Organização Mundial de Saúde (OMS), ainda em 2003. A CQCT adicionou novos elementos à contraditória relação entre agricultura familiar, fumicultura e serviço público de extensão rural.

A referida Convenção foi um tratado selado internacionalmente em favor da saúde, com o intuito de reduzir o tabagismo. Dessa maneira, a CQCT se propôs a "proteger as gerações presentes e futuras das devastadoras consequências sanitárias, sociais, ambientais e econômicas geradas pelo consumo e pela exposição à fumaça do tabaco" (BRASIL, 2011, p. 33). Embora o foco da CQCT seja a redução do consumo de cigarros e de seus congêneres, também são encontradas menções à produção de matéria-prima, isto é, à fumicultura em si, como evidencia o Artigo 4, abaixo transcrito.

\footnotetext{
Artigo 4 - Princípios norteadores. Parágrafo 6 - Devem ser reconhecidos e abordados, no contexto das estratégias nacionais de desenvolvimento sustentável, a importância da assistência técnica e financeira para auxiliar a transição econômica dos produtores agrícolas e trabalhadores cujos meios de vida sejam gravemente afetados em decorrência dos programas de controle do tabaco, nas Partes que sejam países em desenvolvimento, e nas que tenham economias em transição (BRASIL, 2011, p. 33-34).
}

Não somente, também os Artigos 17 e 18 da CQCT tratam da redução das áreas de fumicultura como condição sine qua non para o controle do consumo de seus derivados. No Artigo 17 são recomendadas atividades alternativas economicamente viáveis aos fumicultores e no Artigo 18 é sentenciado o cuidado com o ambiente e a saúde, inclusive no processo de produção de tabaco. 
Dessa maneira, ainda em 2005, com o intuito de viabilizar os artigos anteriormente mencionados, o Brasil elaborou o Programa de Diversificação de Áreas Cultivadas com Tabaco (PNDACT), criado no âmbito do Ministério do Desenvolvimento Agrário (MDA) e implementado pelo serviço público de extensão rural. Em síntese, o PNDACT visa incentivar a realização de outras atividades nas áreas de fumicultura, contribuindo com a contenção do consumo de cigarros e congêneres por meio da diminuição da área cultivada de tabaco, mas sem criar vulnerabilidades socioeconômicas aos fumicultores, como recomendado pela própria Convenção Quadro (BRASIL, 2010b).

No Vale do Rio Pardo, devido aos riscos ambientais, econômicos, sanitários e sociais associados à especialização produtiva na fumicultura, os extensionistas rurais, já antes da CQCT e do PNDACT, vinham incentivando a diversificação e até mesmo a substituição da atividade, com vistas ao cumprimento dos princípios da PNATER de sustentabilidade e de segurança e soberania alimentar. De acordo com os entrevistados, o incentivo à diversificação, principalmente a partir da CQCT, resultou em reduções nas áreas de fumicultura e nos investimentos sobre as mesmas. Como sintetizou um dos agentes do serviço público de extensão rural: "ela [CQCT] teve um efeito negativo para a lavoura do tabaco" (Antônio, 37 anos, extensionista rural). Mas ainda assim nota-se uma resistência dos membros das famílias e das comunidades de fumicultores (sem mencionar os representantes das agroindústrias fumageiras, é claro) em relação à diversificação produtiva pregada pelas políticas públicas elaboradas pelo Estado e implementadas pelos agentes do serviço público de extensão rural.

Uba (2012), em análise de Monte Castelo, Santa Catarina, e Redin (2015), em estudo de Arroio do Tigre, Rio Grande do Sul, enfatizaram a centralidade da fumicultura na reprodução social das famílias rurais, corroborando a dificuldade de avanço das ações de diversificação. Na visão de Vargas e Oliveira (2012), em estudo sobre a diversificação produtiva no Vale do Rio Pardo, em territórios em que a fumicultura é a atividade de maior relevância econômica, as estratégias de diversificação dificilmente são concretizadas.

De maneira semelhante, no Vale do Rio Pardo foi construído um ideário de inconveniência da diversificação produtiva. Dado o sucesso econômico da especialização, os fumicultores começaram a entender a diversificação como desnecessária: seria mais cômodo comprar (ao invés de cultivar) os alimentos de subsistência com o retorno financeiro da comercialização do fumo em folha. Como visualizado no relato do extensionista rural abaixo 
colocado, atualmente, cabe ao serviço público de extensão rural desconstruir esta resistência à diversificação:

[...] muitas propriedades estão investindo só em uma cultura e dali tirando para comprar os mantimentos para subsistência familiar. Há 20 anos atrás se dizia: "oh, planta 1.000 pés de fumo a mais e tu compra todo o resto, né." E realmente, naquela época, a valorização era grande mesmo. E o pessoal internalizou isso e faz isso. Então, agora, a gente precisa desfazer essa mística. Ele tem que produzir em casa tudo para o consumo familiar e que seja uma sobra aquilo ali, não tirar dali para comprar alimentação (Valdir, 55 anos, extensionista rural e ex-instrutor de tabaco).

Além do mencionado, também é importante assinalar o problema de padronização do público-alvo do PNDACT. De acordo com Freitas (2016), a política pública de diversificação não capta a heterogeneidade presente no âmbito da fumicultura, principalmente no que tange à existência de alguns fumicultores mais dependentes dessa atividade (mais especializados) e de outros menos.

Diante de tudo isso, é possível afirmar que a política pública elaborada pelo Estado brasileiro e implementada pelo serviço de extensão rural para atender as demandas da Convenção Quadro, agravou o estigma no entorno da fumicultura, agregando elementos capazes de desencadear uma crise identitária entre os fumicultores: além de não ser inteiramente reconhecida no âmbito da agricultura familiar, a fumicultura passou a ser "combatida" sem que a extensão rural e a política pública por ela implementada incorporassem as diversas realidades dos fumicultores.

Sobre a crise identitária, é interessante ressaltar resultados encontrados em contextos internacionais correlatos. Em estudo realizado no Kentucky, Estados Unidos, referente ao intervalo entre 1979 e 1985, Stallones (1990) sublinhou como as campanhas contra o tabagismo causaram sensações de exclusão sobre os fumicultores: eles sentiam-se dispensáveis na sociedade frente aos esforços realizados contra o seu trabalho, aumentando, assim, o risco de suicídio.

Também Jacques-Jouvenot (2013), Droz et al. (2014) e Bossard et al. (2016), em estudos sobre a realidade da França, mostraram a existência de vínculos entre a ocorrência de suicídio de agricultores e a evolução da Política Agrícola Comum (PAC) da União Europeia. Ao modificar as condições materiais de condução das atividades agropecuárias (em razão de uma série de medidas protecionistas), a PAC afetou as suas condições simbólicas, acentuando a necessidade de conhecimentos administrativos em detrimento dos 
conhecimentos agropecuários, resultando em uma crise de identidade destes agricultores, sendo esta relevante no entendimento de inúmeros casos de suicídio entre os franceses, dado o sentimento de incompetência profissional.

Os estudos acima citados chamam a atenção sobre a capacidade do Estado de interferir sobre o trabalho dos agricultores por meio de mecanismos coercitivos de controle das atividades agropecuárias, como são as políticas públicas. Também Drebes et al. (2018), em um estudo comparativo dos casos do Brasil, da China e da França, notaram as intervenções estatais por meio dos planos jurídico e político como interferentes sobre as condições de vida (e mesmo de morte) dos agricultores.

Como mencionado no início, precisar as causas dos suicídios de fumicultores no Vale do Rio Pardo seria demasiado pretensioso e essa não consiste na intenção do presente estudo. Todavia, considerando a relevância do trabalho no ethos dos fumicultores, como esmiuçado no estudo de Drebes (2019), a repercussão que as contradições entre agricultura familiar, fumicultura e atuação do serviço público de extensão rural por meio da implementação de políticas públicas geram sobre a ocupação dos fumicultores (colocando a fumicultura em posição de atividade econômica, produtiva e trabalhista a ser "combatida"), é conveniente ao desencadeamento de uma crise identitária que, por sua vez, pode apresentar suicídios como consequência.

Todavia, sendo o suicídio um fenômeno complexo e caracterizado pela coexistência de múltiplas motivações, não é possível assegurar esse nexo direto de causa e efeito entre as políticas públicas implementadas pela extensão rural e os suicídios de fumicultores. Por outro lado, ao estudar como os suicídios dos fumicultores são socialmente construídos, também não é possível simplesmente descartar essa linha de raciocínio.

Mesmo atuando na promoção da diversificação produtiva nas áreas de fumicultura do Vale do Rio Pardo e cientes da ocorrência de suicídios entre os fumicultores, os agentes do serviço público de extensão rural não realizam ações de prevenção. Primeiro, porque, como vimos no decorrer do estudo, devido ao sistema integrado de produção e a assistência técnica ofertada pelos instrutores das agroindústrias fumageiras, os extensionistas rurais não estão tão conectados com os fumicultores como estão com outros agricultores familiares. E para os instrutores de tabaco, a proporção de suicídios de fumicultores não parece ser suficiente para constituir um problema, sendo o suicídio um acontecimento comum para toda a população, abarcando as mais diversas ocupações, não apenas os fumicultores. 
Segundo, porque os agentes do serviço público de extensão rural, em sua maior parte formados em áreas de Ciências Agrárias ou então Ciências Sociais, afirmam não possuir o conhecimento necessário para conduzir ações de prevenção aos suicídios ou, nos termos de um entrevistado: "não temos competência profissional para isso e não queremos ser questionados depois" (Valdir, 55 anos, extensionista rural e ex-instrutor de tabaco). Para os agentes do serviço público de extensão rural, esse tipo de trabalho requer intervenções provenientes do serviço de saúde pública do Vale do Rio Pardo.

Entretanto, considerando a possibilidade do suicídio de fumicultores ser relacionado com as particularidades das condições e relações sociais do trabalho na fumicultura, como evidenciado na literatura científica (FALK et al., 1996; ALMEIDA, 2005; MENEGHEL et al., 2012; FARIA et al., 2014; PERES; NETO, 2018; DREBES, 2019), ao se abster da atuação na prevenção dessas mortes, o serviço público de extensão rural promove o reforço da ilusão naturalista no entorno dos suicídios.

Em resumo, a ilusão naturalista é uma tendência, manifestada através de maneiras diversas, de naturalização do fenômeno, entendendo-o como uma fatalidade ou ainda como o resultado de uma enfermidade. Ao atribuir os suicídios à área da saúde, o serviço público de extensão rural reforça a construção social de um viés biológico, fisiológico-psicológico e médico das mortes dos fumicultores no Vale do Rio Pardo, dificultando a compreensão do fenômeno como um problema social que pode guardar relação com condições e relações sociais do trabalho na fumicultura, inclusive com a desvalorização do trabalho do fumicultor diante das políticas públicas que constrangem o seu reconhecimento como agricultores familiares e não estimulam a atividade.

\section{CONSIDERAÇÕES FINAIS}

A compreensão dos casos de suicídios de fumicultores no Vale do Rio Pardo é resultado de processos plurais de construção social, considerando as distintas ações e representações sociais encontradas no campo de poder estruturado acerca da fumicultura. No caso do serviço público de extensão rural, as suas ações e representações sociais costumam refletir o ponto de vista do Estado, principalmente por meio de políticas públicas.

Percebe-se que o desde o início do século XXI, vem sendo construídas relações contraditórias entre o serviço público de extensão rural e a fumicultura. Isso se deve ao fato 
de a fumicultura ser estigmatizada no âmbito da categoria socioprofissional agricultura familiar, que é o público prioritário da extensão rural e, também, ao fato de o referido serviço ser o responsável por conduzir ações de diversificação produtiva nas áreas de fumicultura, com a intenção de controlar o avanço desta atividade e, consequentemente, auxiliar na redução do tabagismo, como proposto pela Convenção Quadro.

Desse modo, os fumicultores entendem o quadro institucional mobilizado pelo serviço público de extensão rural como uma desvalorização de seu trabalho, podendo isto contribuir para crises identitárias e até mesmo suicídios, como já verificado em outros países. De fato, na contemporaneidade, as particularidades das condições e relações sociais no trabalho evidenciam vinculações com muitos casos de suicídio, não só na agricultura, mas também em outras ocupações.

Embora compreendido como um instrumento de resolução de problemas nas áreas rurais, dada sua proximidade com os agricultores, o serviço público de extensão rural não pode ser assim entendido no âmbito de prevenção dos suicídios de fumicultores. Ao não se sentirem profissionalmente competentes para atuar sobre essa problemática e direcionaremna para o serviço público de saúde, os extensionistas rurais acabam reforçando o ideário naturalista dos suicídios de fumicultores, tomados como fatalidades derivadas de enfermidades. Isso obscurece os possíveis vieses sociais envolvidos nos casos e suas vinculações com as condições e relações sociais no trabalho dos fumicultores, dificultando a plena compreensão desse fenômeno, assim como a sua prevenção.

Por fim, vale recordar que o presente estudo não tem a pretensão de delimitar as causas dos suicídios de fumicultores ou mesmo de enfatizar determinados aspectos do fenômeno em detrimento de outros. Conscientes de que o suicídio é um fenômeno social complexo e atravessado por motivações múltiplas e concomitantes, nossa proposta consistiu em analisar o quadro institucional que mobiliza a atuação dos extensionistas rurais diante dos fumicultores e, também, de seus suicídios, o que explica a atenção dedicada à análise das políticas públicas. Vale destacar ainda que o estudo não constrói a ideia de culpabilidade entre extensionistas rurais e suicídios de fumicultores, mas sim traz à tona as limitações da atuação do serviço público de extensão rural no âmbito da prevenção desses suicídios. 


\section{REFERÊNCIAS}

ALMEIDA, G. E. G. Fumo: servidão moderna e violações de direitos humanos. Curitiba: Terra de Direitos, 2005.

ANJOS, F. S.; CALDAS, N. V.; HIRAI, W. G. Mercantilização da agricultura e insegurança alimentar no Sul do Brasil. In: Congresso da SOBER, 46., 2008, Rio Branco. Anais [...]. Rio Branco: UFAC, 2008. Disponível em: https://ageconsearch.umn.edu/record/113195/. Acesso em: 17 nov. 2020.

BOURDIEU, P. Questões de Sociologia. Lisboa: Fim de Século Edições, 2003.

BOURDIEU, P. O campo político. Revista Brasileira de Ciência Política, n. 05, p. 193216, jan./jul. 2011. Disponível em: http://www.scielo.br/pdf/rbcpol/n5/a08n5.pdf. Acesso em: 29 jan. 2019.

BOSSARD, C.; SANTIN, G.; CANU, I. G. Suicide among farmers in France: occupational factors and recent trends. Journal of Agromedicine, v. 21, n. 04, p. 310-315, 2016. Disponível em: https://www.ncbi.nlm.nih.gov/pubmed/27409004. Acesso em: 02 abr. 2020.

BRASIL. Lei n. 11.326 de 24 de julho de 2006. Estabelece as diretrizes para a formulação da Política Nacional da Agricultura Familiar e Empreendimentos Familiares. Brasília: Poder Executivo, 2006. Disponível em: http://www.planalto.gov.br/ccivil_03/_Ato20042006/2006/Lei/L11326.htm. Acesso em: 01 abr. 2020.

BRASIL. Lei n. 12.188 de 11 de janeiro de 2010. Institui a Política Nacional de Assistência Técnica e Extensão Rural para a Agricultura Familiar e Reforma Agrária - PNATER e o Programa Nacional de Assistência Técnica e Extensão Rural na Agricultura Familiar e na Reforma Agrária - PRONATER, altera a Lei no 8.666, de 21 de junho de 1993, e dá outras providências. Brasília: Poder Executivo, 2010a. Disponível em: http://www.planalto.gov.br/ccivil_03/_ato20072010/2010/lei/112188.htm. Acesso em: 02 abr. 2020.

BRASIL. Ações do Ministério do Desenvolvimento Agrário para a diversificação da produção e renda em áreas cultivadas com tabaco no Brasil. Brasília: MDA, 2010b.

BRASIL. Instituto Nacional do Câncer. Convenção-Quadro para o Controle do Tabaco: texto oficial. Rio de Janeiro: INCA, 2011. Disponível em: https://www.inca.gov.br/sites/ufu.sti.inca.local/files//media/document//convencaoquadropar a-controle-do-tabaco-texto-oficial.pdf. Acesso em: 03 abr. 2020.

BRASIL. Decreto n. 9.064 de 31 de maio de 2017. Dispõe sobre a Unidade Familiar de Produção Agrária, institui o Cadastro Nacional da Agricultura Familiar e regulamenta a Lei no 11.326, de 24 de julho de 2006, que estabelece as diretrizes para a formulação da Política Nacional da Agricultura Familiar e empreendimentos familiares rurais. Brasília: Poder Executivo, 2017. Disponível em: http://www.planalto.gov.br/ccivil_03/_Ato20152018/2017/Decreto/D9064.htm. Acesso em: 02 abr. 2020. 
BRASIL. Instituto Nacional do Câncer. Tabagismo: causas e prevenção. 2020. Disponível em: https://www.inca.gov.br/tabagismo. Acesso em: 17 nov. 2020.

DEPONTI, C. M.; SCHNEIDER, S. A Extensão Rural e a diversificação produtiva em áreas de cultivo de tabaco no Rio Grande do Sul: o caso de Dom Feliciano - RS. Revista Ideas, v. 07, n. 02, p. 176-213, 2013. Disponível em: https://r1.ufrrj.br/cpda/ideas/ojs/index.php/ideas/article/view/112/111. Acesso em: 03 abr. 2020.

DREBES, L. M.; BOHNER, T. O. L.; SILVEIRA, V. C. P. Legislação, Política Pública e Suicídio: a influência do Estado sobre vida e morte dos agricultores familiares. Desenvolvimento em Questão, v. 16, n. 44, p. 285-321, jul./set. 2018. Disponível em: https://www.revistas.unijui.edu.br/index.php/desenvolvimentoemquestao/article/view/6570. Acesso em: 01 abr. 2020.

DREBES, L. M. Suicídio de fumicultores familiares: construções de um problema social. 2019. Tese (Doutorado em Extensão Rural) - Universidade Federal de Santa Maria, Santa Maria, 2019. Disponível em: https://repositorio.ufsm.br/bitstream/handle/1/18608/TES_PPGER_2019_DREBES_LAIL A.pdf?sequence $=1 \&$ is Allowed=y. Acesso em: 17 nov. 2020.

DROZ, Y. et al. Malaise en agriculture: une approche interdisciplinaire des politiques agricoles France-Québec-Suisse. Paris: Éditions Karthala, 2014.

FALK, J. W. et al. Suicídio e doença mental em Venâncio Aires - RS: Consequência do Uso de Agrotóxicos Organofosforados? Relatório Preliminar de Pesquisa. Porto Alegre: Comissão de Direitos Humanos da Assembleia Legislativa do Rio Grande do Sul, 1996.

FARIA, N. M. X. et al. Occupational exposure to pesticides, nicotine and minor psychiatric disorders among tobacco farmers in southern Brazil. Neurotoxicology, n. 45, p. 347- 354, 2014. Disponível em: http://www.ncbi.nlm.nih.gov/pubmed/24875484. Acesso em: 01 abr. 2020.

FREITAS, T. D. A diversidade da agricultura familiar produtora de tabaco e a homogeneidade do Programa Nacional de Diversificação: uma política para quem? Estudos Sociedade e Agricultura, v. 24, n. 1, p. 43-69, 2016. Disponível em: https://revistaesa.com/ojs/index.php/esa/article/view/719/438. Acesso em: 22 fev. 2021.

GAZOLLA, M.; SCHNEIDER, S. Qual "Fortalecimento" da Agricultura Familiar? Uma análise do PRONAF crédito de custeio e investimento no Rio Grande do Sul. Revista de Economia e Sociologia Rural, v. 51, n. 01, p. 45-68, 2013. Disponível em: http://www.scielo.br/scielo.php?script=sci_arttext\&pid=S0103-20032013000100003. Acesso em: 03 abr. 2020.

IBGE. Censo Agropecuário 2017. 2017. Disponível em: <https://censos.ibge.gov.br/agro/2017/>. Acesso em: 02 abr. 2020. 
JACQUES-JOUVENOT, D. Stress, suicide et compétence professionelle des producteurs laitiers. 2013. Palestra realizada no Centre Pierre Naville em 18 set. 2013. Disponível em: https://santeindep.sciencesconf.org/data/program/jacques_jouvenot_stress_et_suicide_final. pdf. Acesso em: 03 abr. 2020.

MAZOYER, M.; ROUDART, L. História das agriculturas no mundo: do neolítico à crise contemporânea. São Paulo: Editora UNESP; Brasília: NEAD, 2010.

MELZ, R. L. Os interesses manifestados pelos atores sociais no jogo da fumicultura no Vale do Rio Pardo/RS: uma análise dos fatos sociais produzidos de 2002 a 2005. 2017. Dissertação (Mestrado em Administração) - Universidade Federal do Rio Grande do Sul, Porto Alegre, $2017 . \quad$ Disponível em: https://lume.ufrgs.br/bitstream/handle/10183/168996/001047792.pdf?sequence=1\&isAllow ed=y. Acesso em: 02 abr. 2020.

MENEGHEL, S. N.; CECCON, R. F.; HESLER, L. Z. O suicídio na rota dos galpões de fumo: um olhar etnográfico. Revista Interface, s. 01, 2012. Disponível em: http://conferencias.redeunida.org.br/ocs/index.php/congresso2012/CRU10/paper/view/5513 . Acesso em: 01 abr. 2020.

NEVES, D. P. Agricultura familiar: quantos ancoradouros! In: FERNANDES, B. M.; MARQUES, M. I. M.; SUZUKI, J. C. (Org.). Geografia Agrária: teoria e poder. São Paulo: Expressão Popular, 2007. p. 211-270.

PAULILO, M. I. Produtor e agroindústria: consensos e dissensos. Florianópolis: Ed. da UFSC, 1990.

PERES, J.; NETO, M. Roucos e sufocados: a indústria do cigarro está viva e matando. São Paulo: Elefante, 2018.

PICOLOTTO, E. L. As mãos que alimentam a nação: agricultura familiar sindicalismo e política. 2011. Tese (Doutorado em Ciências) - Universidade Federal Rural do Rio de Janeiro, Rio de Janeiro, 2011. Disponível em: http://institucional.ufrrj.br/portalcpda/files/2018/08/2011.tese_.everton_picolotto.pdf.

Acesso em: 03 abr. 2020.

REDIN, E. Família rural e produção de tabaco: estratégias de reprodução social em Arroio do Tigre/RS. 2015. Tese (Doutorado em Extensão Rural) - Universidade Federal de Santa Maria, Santa Maria, 2015. Disponível em: https://repositorio.ufsm.br/bitstream/handle/1/3822/REDIN\%2c\%20EZEQUIEL.pdf?seque nce $=1 \&$ isAllowed $=y$. Acesso em: 01 abr. 2020.

RIO GRANDE DO SUL. Secretaria Estadual da Saúde. Boletim de Vigilância Epidemiológica de Suicídio e Tentativa de Suicídio. 2018. Disponível em: https://cevs.rs.gov.br/upload/arquivos/201809/05162957-boletimdevigilanciaepidemiologica-de-suicidio-n1-2018.pdf. Acesso em: 15 abr. 2019. 
SCHNEIDER, S. Agricultura familiar e desenvolvimento rural endógeno: elementos teóricos e um estudo de caso. In: FROEHLICH, J. M.; DIESEL, V. (Orgs.). Desenvolvimento rural: tendências e debates contemporâneos. Ijuí: Editora Unijuí, 2006. p. 15-63.

STALLONES, L. Suicide mortality among Kentucky farmers, 1979-1985. Suicide and LifeThreatening Behavior, v. 20, n. 02, p. 156-163, 1990. Disponível em: https://www.ncbi.nlm.nih.gov/pubmed/2385858. Acesso em: 02 abr. 2020.

UBA, D. Agricultores familiares e diversificação em áreas de cultivo de tabaco: o caso de Monte Castelo/SC. 2012. Dissertação (Mestrado em Extensão Rural) - Universidade Federal de Santa Maria, Santa Maria, 2012. Disponível em: http://www.bvshistoria.coc.fiocruz.br/lildbi/docsonline/get.php?id=820. Acesso em: 01 abr. 2020.

VARGAS, M. A.; OLIVEIRA, B. F. Estratégias de diversificação em áreas de cultivo de tabaco no Vale do Rio Pardo: uma análise comparativa. Revista de Economia e Sociologia Rural, v. 50, n. 01, p. 175-192, jan./mar. 2012. Disponível em: http://www.scielo.br/scielo.php?script=sci_arttext\&pid=S0103-20032012000100010. Acesso em: 03 abr. 2020. 